\title{
Mathematical Modelling of Heat and Mass Transfer in a Roof Type Solar Distillation System
}

\author{
F. Onoroh ${ }^{\mathrm{a}, *}$, S. S. Folorunsho ${ }^{\mathrm{a}}$, M. Ogbonnaya ${ }^{\mathrm{a}}$, U. P. Onochie ${ }^{\mathrm{b}}$ \\ ${ }^{a}$ Department of Mechanical Engineering, University of Lagos, Akoka, Yaba, Lagos State, NIGERIA. \\ ${ }^{b}$ Mechanical Engineering Department, Alex Ekwueme Federal University, Ndufu-alike, Ebonyi State, NIGERIA.
}

\begin{abstract}
This research examined the performance of a roof type solar distillation system. A model was developed that captured the influence of the cover angle on still performance in terms of evaluating the heat transfer coefficient, yield and efficiency. The previous models of evaluating these matric has been shown to be unsatisfactory due to over prediction. The objectives are to clarify the misconception on the efficiency, to validate the derived expression for the Nusselt's number of condensation under an inclined surface and to perform sensitivity analysis on the dimensionless parameters with derived models. The derived model has a practical significance because it provides much information on the dependence of the heat transfer coefficient on the cover angle. The model was solved with MATLAB, and results show a well correlated trends with the established work of literature and the proposed model having the lest efficiency as the model is without the over prediction inherent in other models due to non-inclusion of evaporation in the analysis of free convection of air. The peak yield of all the models occurs at about 11:00 AM, with the proposed model having a peak yield of about $0.045 \mathrm{~kg}$.
\end{abstract}

Keywords: distillation, solar still, Nusselt number, insolation, heat transfer coefficient, condensate

\section{INTRODUCTION}

Water is essential for life and it is indispensable to humans, industrial and agricultural purposes. Ninety percent $(90 \%)$ of the water sources on earth is salt water and is unhygienic for human consumption [1]. The demand for fresh water is exponentially increasing causing a great imbalance in demand and supply, as most of the naturally available water is impure and not fit for drinking and thus require some form of treatment [2].

Water treatment plants consumes a lot of energy which invariably lead to environmental degradation, global warming and fuel supply issues [3]. Solar energy can be harnessed to provide fresh water supply in decentralized system as it is relatively abundant in temperate regions [2].

Solar stills are new technology for using solar irradiation to purify water [4], they provide fresh water to communities at a relatively cheap cost compared to fossil fuel energy sources and without attendant harmful emissions to the environment [4].

Figure 1 shows a schematic of basin solar still and energy flows diagram. The solar still is filled

\footnotetext{
${ }^{*}$ Corresponding author (Tel: +234 (0)807 464 8666)

Email addresses: fonoroh@unilag.edu.ng (F. Onoroh), folisurdique@gmail.com (S. S. Folorunsho), mogbonnaya@unilag.edu.ng (M. Ogbonnaya), onochieuche@yahoo.com (U. P. Onochie)
}

with impure water, solar radiation is focused on a condensing cover which heat up the mass of water till evaporation, the resultant vapour is separated from the impurities and subsequently condenses on an inclined cover and flows to collection trough. The productivity of the solar still is solely dependent on the intensity of the solar radiation [5].

\section{REVIEW OF THERMAL SOLAR STILL MODELS}

Due to density variations occasioned by temperature and concentration differentials, natural convection take place in solar stills, and the heat flux is mathematically defined as:

$$
q_{c}=h_{c, w-g} A_{g}\left(T_{w}-T_{g}\right)
$$

Where $h_{c, w-g}$ is the convective heat transfer coefficient from water to glass, $\mathrm{W} / \mathrm{m}^{2} \mathrm{~K}, A_{g}$ is the surface area of glass cover, $\mathrm{m}^{2}, T_{w}$ is the water temperature, ${ }^{\circ} \mathrm{C}, T_{g}$ is the glass temperature, ${ }^{\circ} \mathrm{C}$. Figure 2 shows a single-slope solar still, with constant glass and water temperature under ideal conditions of flow.

\subsection{Nader and Esfahani Model}

Nader and Esfahani [6], in a numerical study expressed the Nusselt's number in terms of the aspect ratio as:

$$
N u=0.28 R a^{0.25} A^{-0.16}
$$




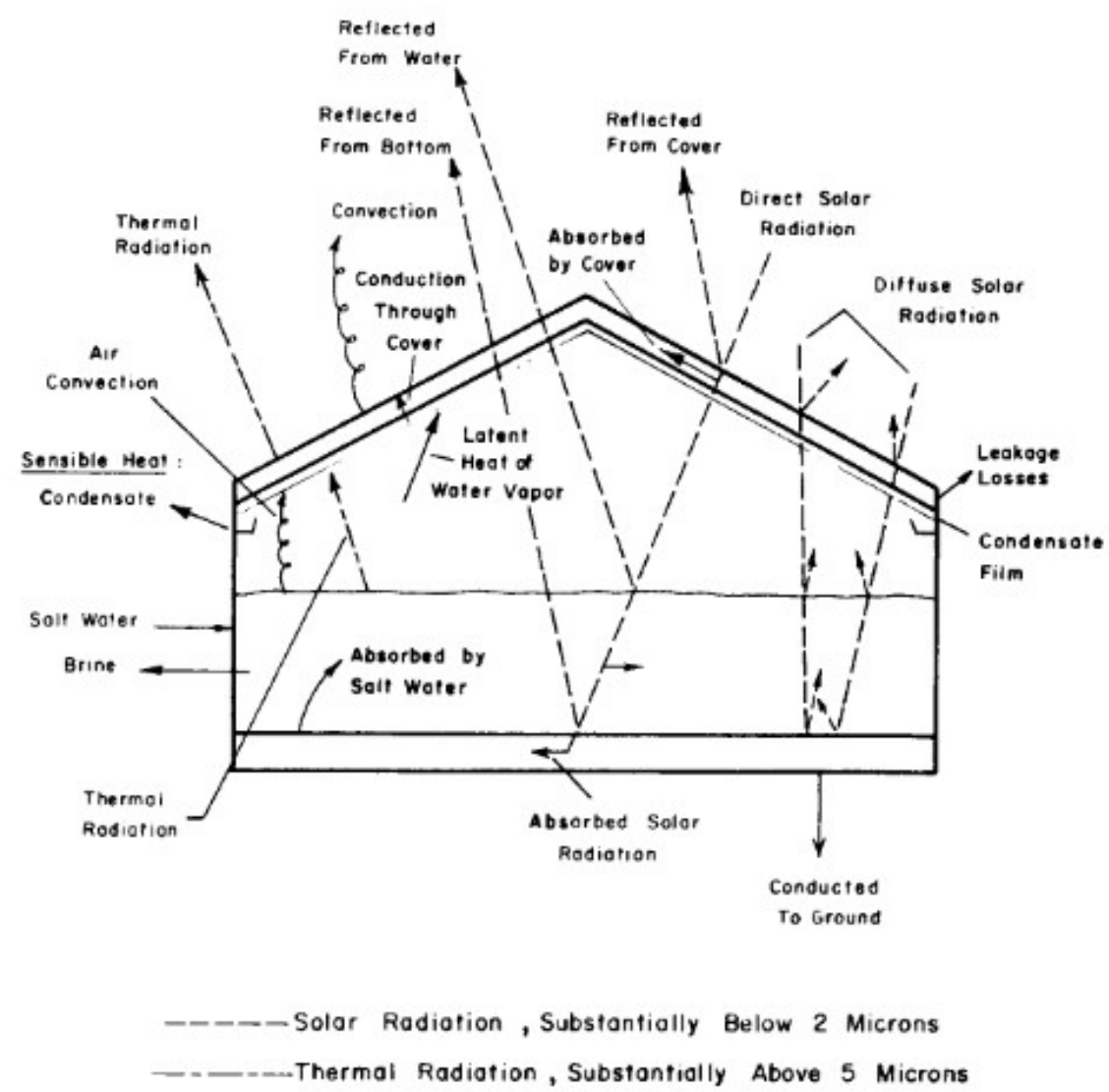

Figure 1: Basin solar still and Principal Energy Flows [7].

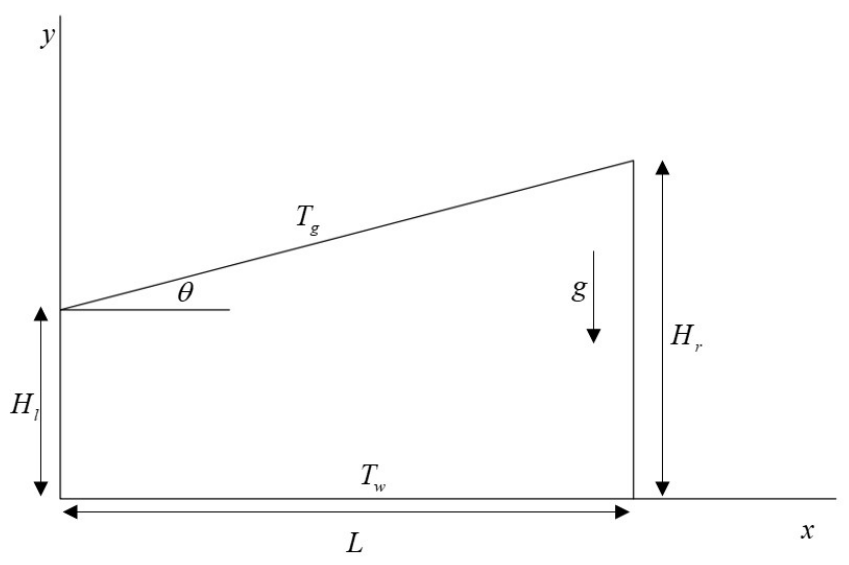

Figure 2: Geometry and coordinate system of the solar still [6].

where

$$
R a=\frac{\rho^{2} g \beta C_{p H^{3} \Delta T}}{\mu} k
$$

With reference to Fig. 2,

$$
\begin{gathered}
A=\frac{L}{H} \\
H=\frac{H_{l}+H_{r}}{2}
\end{gathered}
$$

Where $R a$ is the Rayleigh number, $\rho$ is the density of water vapour, $\mathrm{kg} / \mathrm{m}^{3}, \mathrm{~g}$ is the acceleration due to gravity, $\mathrm{m} / \mathrm{s}^{2}, \beta$ is the coefficient of cubical expansion of water vapour, $/ \mathrm{K}, \mathrm{H}$ is the average height of solar still, $\mathrm{m}, \Delta \mathrm{T}$ is the temperature gradient, ${ }^{\circ} \mathrm{C}$, $\mu$ is the dynamic viscosity of water water, Pa.s, $k$ is the thermal conductivity of water vapour, $\mathrm{W} / \mathrm{mK}$, A is the aspect ratio and $L$ is the horizontal distance of the solar still, $\mathrm{m}$.

\subsection{Dunkle's Model}

This model is based on Sharpley and Boelter, [8] and Jakob's relations, finds wide applications in computing heat transfer coefficient and is defined as [9]:

$$
h_{c, w-g}=0.884(\Delta T)^{\frac{1}{3}}
$$

where

$$
\begin{gathered}
\Delta T=\left[\left(T_{w}-T_{g}\right)+\frac{\left(P_{w}-P_{g i}\right)\left(T_{w}+273\right)}{268900-P_{w}}\right] \\
P_{w}=\exp \left(25.317-\frac{5144}{T_{w}+273}\right) \\
P_{g i}=\exp \left(25.317-\frac{5144}{T_{g i}+273}\right)
\end{gathered}
$$

$P_{w}$ is the partial pressure of vapour at water temperature, $\mathrm{Pa} P_{g i}$ is the partial pressure of vapour at inner glass temperature, $\mathrm{Pa}$. 
Table 1: Expressions to compute properties of humid air [10].

\begin{tabular}{lcc}
\hline Quantity & & Expression \\
\hline Specific heat & $C_{p}$ & $999.2+0.1434 \times T_{i}+1.101 \times 10^{-4} \times T_{i}^{2}-6.758 \times 10^{-8} \times T_{i}^{3}$ \\
Density & $\rho_{v}$ & $\frac{353.44}{T_{i}+273.15}$ \\
Thermal conductivity & $k_{v}$ & $0.0244+\left(0.7673 \times 10^{-4} \times T_{i}\right)$ \\
Viscosity & $\mu_{v}$ & $1.718 \times 10^{-5}+4.62 \times 10^{-8} \times T_{i}$ \\
Latent heat of vaporization & $h_{f g}$ & $3.2615 \times 10^{6} \times\left[1-\left(7.616 \times 10^{-4} \times T_{i}\right]\right.$ for $T_{i}>70^{\circ} \mathrm{C}$ \\
of water & & $2.4935 \times 10^{6} \times\left[1-\left(\begin{array}{l}\left.9.4749 \times 10^{-4} \times T_{i}+1.3132 \times 10^{-7} \times T_{i}^{2}\right) \\
-4.7947 \times 10^{-9} \times T_{i}^{3}\end{array}\right)\right]$ for $T<70^{\circ} \mathrm{C}$ \\
& & $\exp \left(25.317-\frac{5144}{T_{g i}+273.15}\right)$ \\
Partial saturated pressure at & $P_{g i}$ & $\exp \left(25.317-\frac{5144}{T_{w}+273.15}\right)$ \\
glass temperature & & 1 \\
Partial saturated pressure at & $P_{w}$ & $\frac{1}{T_{i}+273.15}$ \\
water temperatures & &
\end{tabular}

Another form of Dunkle's model is:

$$
N u=0.075 R a^{\frac{1}{3}}
$$

The properties in Table 1, are computed using the mid film temperature defined as:

$$
T_{i}=\frac{T_{g}+T_{w}}{2}
$$

\subsection{Corcione's Model}

Corcione [11], relation for computation of Nusselt number for a horizontal square cavity is defined as:

$$
N u=0.21\left(\frac{L}{H}\right)^{0.09} R a^{0.25}
$$

\subsection{Shawaqfeht's Model}

In an experimental study, Shawaqfeht [12], proposed two empirical correlations the Bulk Motion and Chilton-Colburn analogy. The empirical correlation for the Bulk- Motion model is expressed as:

$$
N u_{b m}=0.057 R a^{\frac{1}{3}}
$$

While the relation for Chiton - Colburn [13] is given as:

$$
N u_{c c}=0.051 R a^{\frac{1}{3}}
$$

\section{MODELLING OF SOLAR STILL}

\subsection{Heat Transfer Coefficients in a Conven- tional Solar Still}

The three relevant heat transfer coefficient are Convective heat transfer coefficient, Radiative heat transfer coefficient and Evaporative heat transfer coefficient. The convective heat transfers between a water surface to the condensing glass lid:

$$
q_{c w}=h_{c w}\left(T_{w}-T_{g}\right)
$$

Where

$$
h_{c w}=\frac{0.88\left[\left(T_{w}-T_{g}\right)+\left(P_{w}-P_{g}\right)\left(T_{w}+273\right)\right.}{\left(268.9 \times 10^{3}-P_{w}\right)^{\frac{1}{3}}}
$$

The Radiative heat transfer from the water surface to the condensing cover:

$$
q_{r w}=h_{r w}\left(T_{w}-T_{g}\right)
$$

where

$$
h_{r w}=\varepsilon_{\text {effect }} \sigma\left(\left(T_{w}+273\right)^{2}+\left(T_{g}+273\right)^{2}\right)
$$

$$
\varepsilon_{\text {effect }}=\left(\frac{1}{\varepsilon_{g}}+\frac{1}{\varepsilon_{w}}-1\right)^{-1}
$$

$\varepsilon_{g}=\varepsilon_{w}=0.9$

The evaporative heat transfer:

$$
q_{e w}=h_{e w}\left(T_{w}-T_{g}\right)
$$

where

$$
h_{e w}=16.27 \times 10^{-3} \times h_{c w} \times \frac{P_{w}-P_{g}}{T_{w}-T_{g}}
$$

Referring to Fig. 2, in the absence of vapour leakage and temperature gradients between the glass cover and basin water, the energy balance equations at steady state can be written for the glass cover using relation extracted from studies of [1416]:

$q_{r, g-a} A_{A}+q_{c, g-a} A_{g}=H_{s} A_{g}+\left(q_{e w}+q_{r, w-g}+q_{c, w-g}\right) A_{w}$

where $q_{r, g-a}$ is the radiative heat transfer from glass to air, $\mathrm{W} / \mathrm{m}^{2}, q_{c, g-a}$ is the convective heat transfer from glass to air, $\mathrm{W} / \mathrm{m}^{2}, q_{c, w-g}$ is the convective heat transfer from water to glass, $\mathrm{W} / \mathrm{m}^{2}$, $A_{w}$ is the surface area of water, $\mathrm{m}^{2}$ and $H_{s}$ is the 
total global solar radiation rate, $\mathrm{W} / \mathrm{m}^{2}$. For the basin water, energy balance equations at steady state can be written for the glass cover as:

$\left(q_{r, w-g}+q_{c, w-g}+q_{e w}\right) A_{w}+q_{b} A_{w}+2 q_{s} A_{s}=\alpha \tau_{g} H_{s} A_{w}$

The efficiency of the still is thus expressed as:

$$
\eta_{0}=\frac{q_{e w}}{H_{s}}
$$

However, on measurement of the condensation rate, the efficiency of the still is better defined as [17]:

$$
\eta_{0}=\frac{m_{w} h_{f g}^{\prime}}{H_{s}}
$$

Where $m_{w}$ equals flow rate of condensate, $\mathrm{kg} / \mathrm{s}$, $h_{f g}^{\prime}$ equals enthalpy of evaporation of water at $T_{s}$, $\mathrm{kJ} / \mathrm{kg}$.

\subsection{Maximum Efficiency in Roof Type Solar Stills}

Figure 3 depicts the heat fluxes in a single solar still. Energy balance for the condensate per unit area is expressed as:

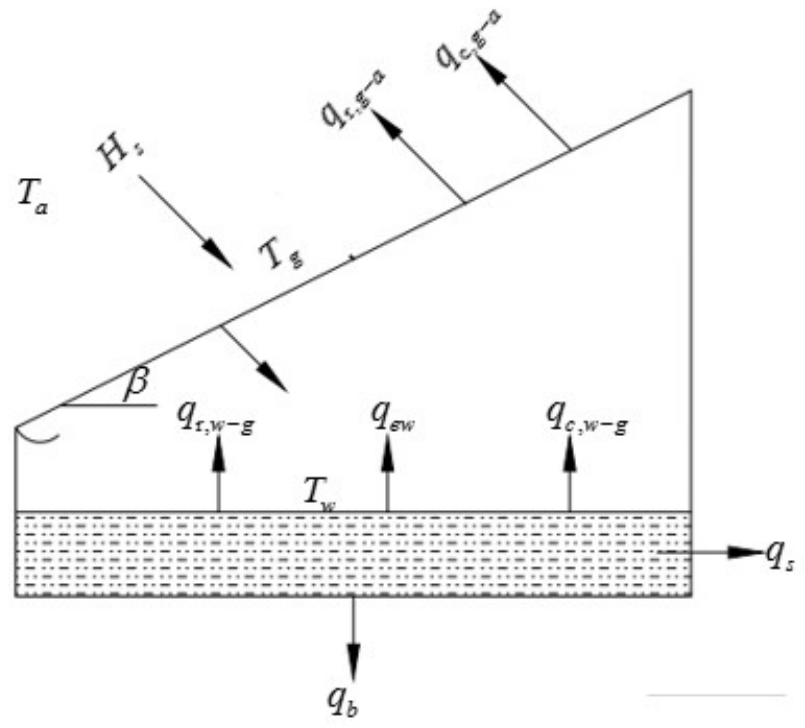

Figure 3: Heat fluxes in a still [18].

$$
m_{w} h_{f g}=h_{c o n}\left(T_{s}-T_{g}\right)=\alpha_{c} \tau_{g} H_{s}+q_{e, w v}
$$

Energy balance for the bowl water is expressed in Eq. (23) as:

$$
\alpha_{w} \tau_{g} H_{s}=q_{e w}+L 1
$$

For the constant temperature air-water vapour mixture:

$$
\alpha_{w v} \tau_{g} H_{s}=q_{e, w v}+L 2
$$

Where $L 1$, and $L 2$ represents losses due to thermal inertia of water and vapour leakage.

Assuming no losses:

$$
L 1=0=L 2
$$

Combining Eqs. (23), (25) and (25) results in Eq. (26) as follows:

$$
\alpha_{w} \tau_{w v}+\tau_{g} H+\alpha_{w v} \tau_{g} H_{s}=q_{e, w v}
$$

Substituting Eq. (26) into Eq. (22), gives:

$$
m_{w} h_{f g}=\left(\alpha_{c}+\alpha_{w v}+\alpha_{w} \tau_{w v}\right) \tau_{g} H_{s}
$$

The efficiency, $\eta_{o}$, is thus expressed as:

$$
\eta_{o}=\left(\alpha_{c}+\alpha_{w v}+\alpha_{w} \tau_{w v}\right) \tau_{g}
$$

Using Eqs. (23) and (24), the ideal efficiency, $\eta_{o, i d}$, can be written as:

$$
\eta_{o, i d}=\alpha_{w} \tau_{w v} \tau_{g}
$$

The efficiency of the still, $\eta_{o}$, equals ideal efficiency, $\eta_{o, i d}$, if there are no losses.

\subsection{Heat and Mass Transfer in Roof-Type So- lar Stills}

Figure 4 shows air-water vapour circulation in a solar still with water-cooled inclined cover at $30^{\circ}$.

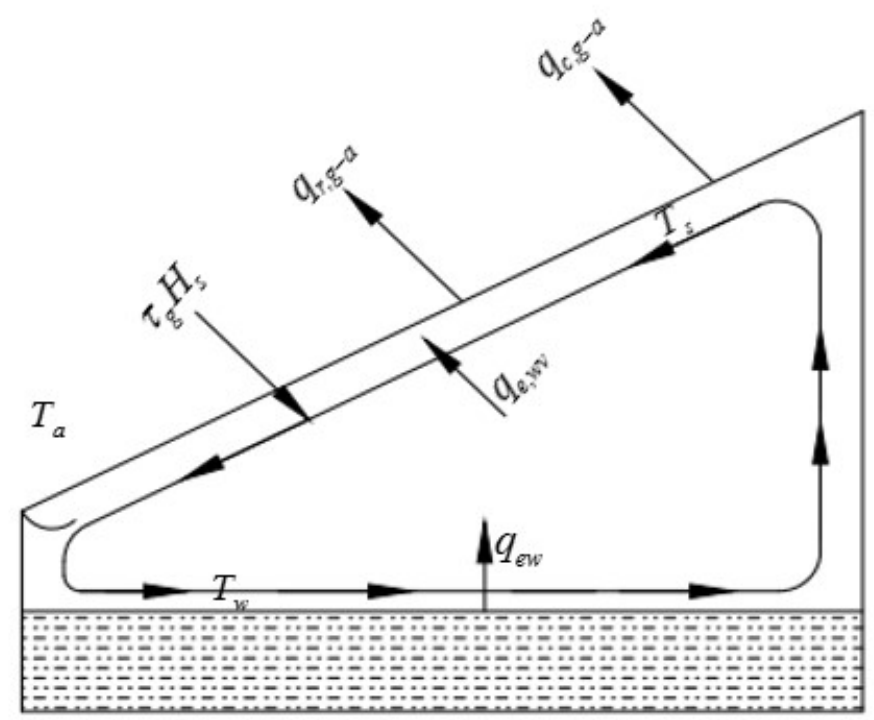

Figure 4: Circulation of Air-Water Vapor in a Single Slope Still [17]]

The temperature profile in the still is as shown in Fig. 5. The air-water vapour mixture adjoining the condensate flows alongside the condensate [19]. 


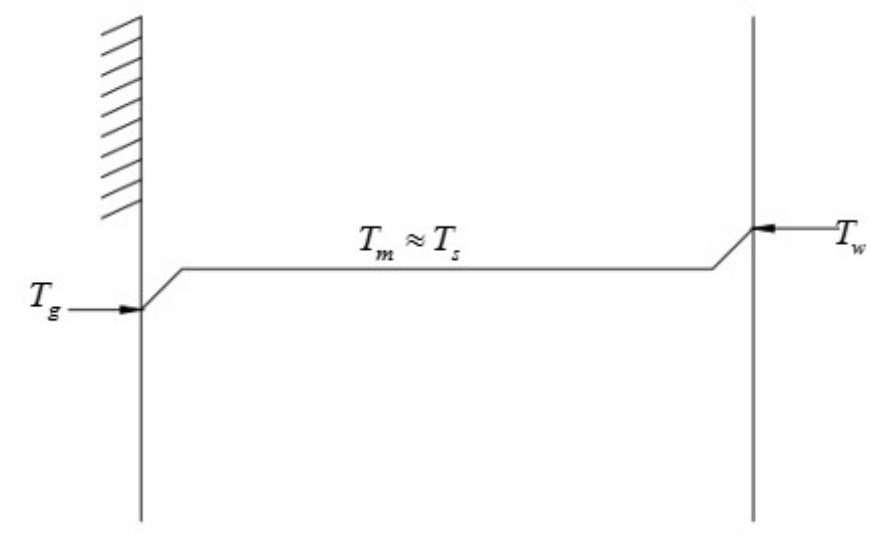

Figure 5: Temperature Profile in a Single-Slope Solar Still

The heat transfer coefficients of evaporation and condensation at the uppermost layer are evaluated using Eqs. (29) and (30) extracted from the study of [19] given as follows:

$$
N u_{e v}=39.8 \varepsilon_{e v}(G r \times P r)_{e v}^{0.17}
$$

For

$$
2.17 \times 10^{6} \leq(G r \times P r)_{e v} \leq 1.78 \times 10^{7}
$$

and

$$
N u_{c o n}=1.413 \times 10^{-4} \varepsilon_{c o n}\left(G r_{c o n} \times P r_{c o n}\right)
$$

for

$$
2.35 \times 10^{5} \leq\left(G r_{c o n} \times P r_{c o n}\right) \leq 2.51 \times 10^{7}
$$

Where $\varepsilon_{e v}$ and $\varepsilon_{c o n}$ are the equilibrium volumetric fraction of water vapor. Eq. (31) is for cover inclined at about $30^{\circ}$, while Eq. (30) is independent of cover angle.

\subsection{Analysis of Film Condensation on the Underside of an Inclined Plate}

The influence of cover angle, $\beta$, on heat transfer coefficient can be analyzed using Fig. 6 . The film thickness, $\delta$, increasing down the slope.

$$
\tau_{z}=g \sin \beta\left(\rho_{l}-\rho_{v}\right)(\delta-y)
$$

But

$$
\tau_{z}=\mu_{l} \frac{d v_{z}}{d y}
$$

In the light of Eqs. (32) and (33)

$$
\int \frac{d v_{z}}{d y}=\frac{1}{\mu_{l}} \int g \sin \beta\left(\rho_{l}-\rho_{v}\right)(\delta-y) d y
$$

At

$y=0, v_{z}=0$

Therefore

$$
v_{z}=\frac{1}{\mu_{l}} g \sin \beta\left(\rho_{l}-\rho_{v}\right)\left(\delta y=\frac{y^{2}}{2}\right)
$$

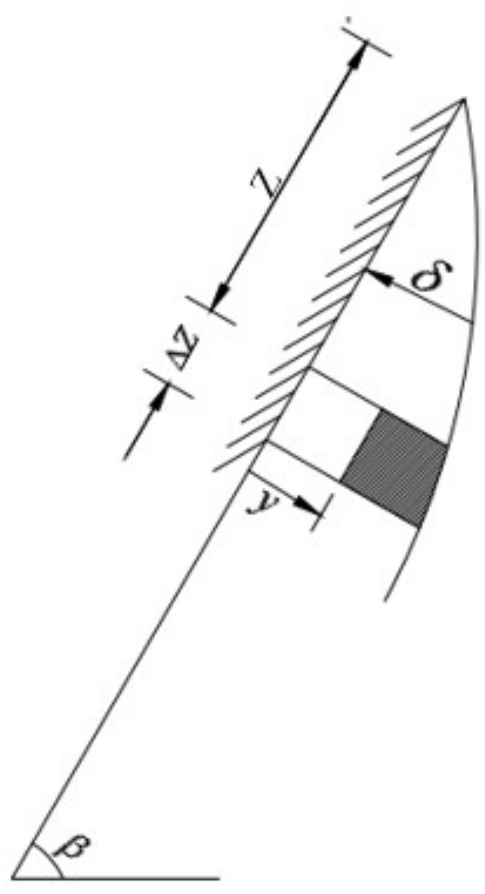

Figure 6: Film Condensation on the Underside of an inclined plate [18].

The liquid flow rate in the film per unit width is defined as:

$$
\Gamma=\int_{0}^{\delta} \rho_{l} v_{z} d y
$$

Substituting Eq. (34) into Eq. (35) gives:

$$
\Gamma=\int_{0}^{\delta} \rho_{l} \frac{1}{\mu_{l}} g \sin \beta\left(\rho_{l}-\rho_{v}\right)\left(\delta y=\frac{y^{2}}{2}\right) d y
$$

By simplification Eq. (35) becomes:

$$
\Gamma=\frac{\rho_{l} g \sin \beta\left(\rho_{l}-\rho_{v}\right) \delta^{3}}{3 \mu_{l}}
$$

Differentiating Eq. (37) with respect to film thickness yields:

$$
\frac{d \Gamma}{d \delta}=\frac{\rho_{l} g \sin \beta\left(\rho_{l}-\rho_{v}\right) \delta^{3}}{3 \mu_{l}}
$$

Applying energy balance principle to equation Eq. (38) gives:

$$
\frac{k_{l}\left(T_{s}-T_{g}\right)}{\delta}=\left[h_{f g}+\frac{1}{\Gamma} \int_{0}^{\delta} \rho_{l} v_{z} c_{p}\left(T_{s}-T\right) d y\right] \frac{d \Gamma}{d z}
$$

The linear temperature distribution is given as:

$$
\frac{T_{s}-T}{T_{s}-T_{g}}=1-\frac{y}{\delta}
$$


Substitute Eqs. (34), (35), (36) and (40) into Eq. (39), noting that $\delta=0$ at $z=0$ gives:

$$
\begin{aligned}
& \frac{k_{l}\left(T_{s}-T_{g}\right)}{\delta}= \\
& {\left[\begin{array}{l}
h_{f g}+\frac{3 \mu c_{p}\left(T_{s}-T_{g}\right)}{\rho_{l} g \sin \beta\left(\rho_{l}-\rho_{v}\right) \delta^{3}}\left(\rho_{l} \frac{1}{\mu_{l}} \mu_{l} g \sin \beta\left(\rho_{l}-\rho_{v}\right)\right) \times \\
\int_{0}^{\delta}\left(\delta_{y}-\frac{y^{2}}{2}\right)\left(1-\frac{y}{\delta}\right) d y
\end{array}\right] \frac{d \Gamma}{d z}}
\end{aligned}
$$

By simplification equation (42) gives:

$$
\frac{k_{l}\left(T_{s}-T_{g}\right)}{\delta}=\left[h_{f g}+\frac{3}{8} c_{p}\left(T_{s}-T_{g}\right)\right] \frac{d \Gamma}{d z}
$$

And can be expressed as:

$$
\frac{k_{l}\left(T_{s}-T_{g}\right)}{\delta}=h_{f g} \frac{d \Gamma}{d z}
$$

where

$$
\frac{d \Gamma}{d z}=\frac{d \Gamma}{d \delta} \times \frac{d \delta}{d z}
$$

Thus

$$
\frac{k_{l}\left(T_{s}-T_{g}\right)}{\delta}=h_{f g} \times \frac{d \Gamma}{d \delta} \times \frac{d \delta}{d z}
$$

Therefore

$$
\frac{k_{l}\left(T_{s}-T_{g}\right)}{\delta}=h_{f g}^{\prime} \times \frac{d \Gamma}{d \delta} \times \frac{d \delta}{d z}
$$

Substituting Eq. (38) into Eq. (45) gives Eq. (46):

$$
\frac{k_{l}\left(T_{s}-T_{g}\right) \mu_{l} d z}{\rho_{l} g \sin \beta\left(\rho_{l}-\rho_{v}\right) h_{f g}}=\delta^{3} d \delta
$$

Integrating both sides and applying the boundary condition, $z=0, \delta=0$ yield the thickness of the condensate layer as a function of the position $\mathrm{z}$ along the plate as:

$$
\frac{\delta^{4}}{4}=\frac{k_{l}\left(T_{s}-T_{g}\right) \mu_{l} Z}{\rho_{l} g \sin \beta\left(\rho_{l}-\rho_{v}\right) h_{f g}^{\prime}}
$$

Heat flux at the glass plate is calculated using Eq. (47):

$$
\left(\frac{q}{A}\right)_{g}=-k_{l}\left(\frac{d T}{d y}\right)_{g}
$$

From Eq. (40)

$$
\left(\frac{d T}{d y}\right)_{g}=\left(T_{s}-T_{g}\right) \times \frac{1}{\delta}
$$

Thus

$$
\left(\frac{q}{A}\right)_{g}=-k_{l}\left(\left(T_{s}-T_{g}\right) \times \frac{1}{\delta}\right)_{g}
$$

Local condensation heat transfer coefficient $h_{z, c o n}$

$$
h_{z, c o n}=-\left(\frac{q}{A}\right)_{g}
$$

Substituting Eq. (49), into Eq. (50) and upon simplification gives:

$$
h_{z, c o n}=\frac{k}{\delta}
$$

In the light of Eq. (47) and Eq. (51), then:

$$
h_{z, \text { con }}=\left[\frac{k_{l}^{3} \rho_{l} g\left(\rho_{1}-\rho_{v}\right) h_{f g}^{\prime} \sin \beta}{4\left(T_{s}-T_{g}\right) \mu_{l} Z}\right]^{\frac{1}{4}}
$$

Average condensation heat transfer coefficient:

$$
h_{z, c o n}=\frac{1}{L} \int_{0}^{L} h_{z, c o n} d z
$$

Evaluation Eq. (53) gives:

$$
h_{z, \text { con }}=0.943\left[\frac{k_{l}^{3} \rho_{l} g\left(\rho_{1}-\rho_{v}\right) h_{f g}^{\prime} \sin \beta}{4\left(T_{s}-T_{g}\right) \mu_{l} L}\right]
$$

Using the dimensionless parameters:

$$
\begin{gathered}
N u_{\text {con }}=\frac{h_{c o n} \times L}{k} \\
G r_{c o n}=\frac{g \beta\left(T_{s}-T_{g}\right) L^{3}}{v_{2}} \\
P r_{c o n}=\frac{v}{\alpha} \\
J a *=\frac{c_{p}\left(T_{s}-T_{g}\right.}{h_{f g}}
\end{gathered}
$$

Where $P r_{c o n}$ is the Prandtl number for condensation, $v$ is the kinematic viscosity, $\mathrm{m}^{2} / \mathrm{s}, \alpha$ is the thermal diffusivity, $\mathrm{m}^{2} / \mathrm{s}, J a *$ is the modified Jakob's number for condensation, $c_{p}$ is the specific heat capacity of water vapour, J/kgK, $T_{s}$ and $T_{g}$ are surface and glass temperature respectively, ${ }^{\circ} \mathrm{C}$, is enthalpy of condensation of water vapour, $\mathrm{J} / \mathrm{kg}$.

The Nusselt's Number for condensation is thus obtained as:

$$
N u_{c o n}=0.738\left[G r_{c o n} \times P r_{c o n} \times \frac{\sin \beta}{J a *}\right]^{\frac{1}{4}}
$$

The heat flux utilized during condensation is obtained as follows:

$$
q_{c o n}=h_{c o n}\left(T_{s}-T_{g}\right)
$$

The productivity of the still is defined by:

$$
\dot{m}=\frac{q_{c o n}}{h_{f g}}
$$

Efficiency, $\eta_{o}$, of the still is calculated as follows:

$$
\eta_{o}=\frac{q_{c o n}}{H_{s}}
$$

Where $q_{c o n}$ is the condensation heat flux, J/kg and is the solar radiation intensity, $\mathrm{W} / \mathrm{m}^{2}$. 


\section{RESULTS AND DISCUSSION}

The accuracy of the derived model is compared with other thermals models using virtual test case as shown in Table 2, at different temperature values of the inner glass and water respectively.

Table 2: Virtual data for Simulations.

\begin{tabular}{lcc}
\hline Case No & \multicolumn{2}{c}{ Temperature } \\
& $T_{w}\left({ }^{\circ} \mathrm{C}\right)$ & $T_{g}\left({ }^{\circ} \mathrm{C}\right)$ \\
\hline 1 & 40 & 30 \\
2 & 50 & 40 \\
3 & 60 & 50 \\
4 & 70 & 60 \\
\hline
\end{tabular}

\subsection{Variation of Nusselt Number with Glass and Water temperatures}

Figure 7 illustrates the variation of Nusselt Number with temperature values of the inner glass and water respectively for the virtual data. It can be clearly seen that the derived model has the same trend as the thermal models reported in literature. The theory of heat and mass transfer

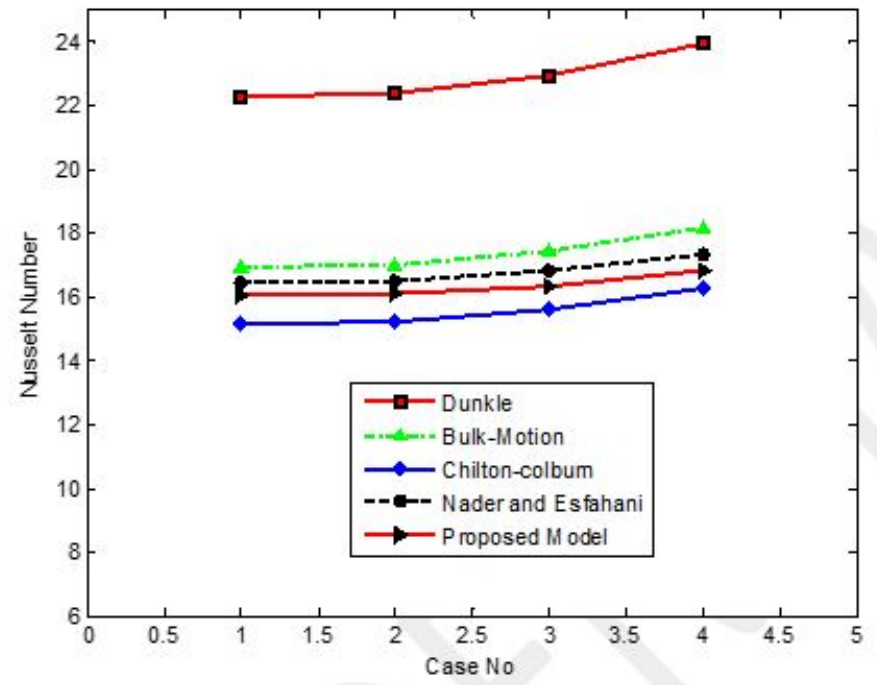

Figure 7: Nusselt number of different Models with Virtual data.

in the still was originally proposed by Dunkle [9]. The drawback of his analysis and used by other investigators is due to the assumptions of free convection of air without evaporation and thus leading to over prediction.

The graphs show a seemingly linear relationship between the temperatures and the Nusselt number.

\subsection{Variation of Still Productivity of differ- ent Models with Time}

Figure 8 shows the comparison of the hourly yield of the solar still between the proposed model and reported models in literature. The models tend to exhibit same profile with the derived model recording the lest productivity due to over

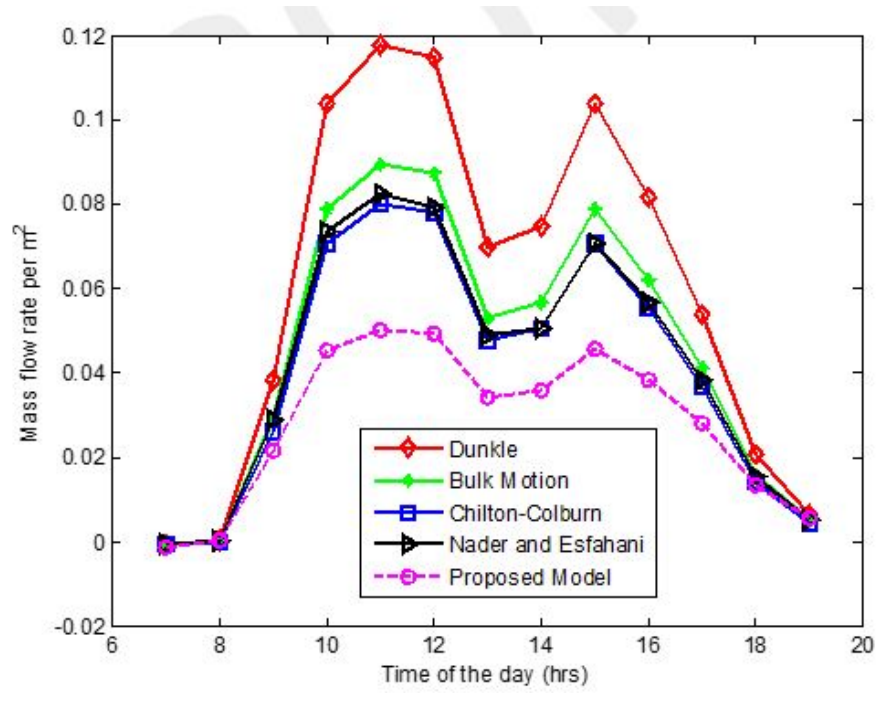

Figure 8: Comparison of still productivity between the present study and the reported works of literature.

estimation of the yield according to Shawaqfeht [12]. The peak yield of all the models occurs at about 11:00 AM, with the proposed model having a peak yield of about $0.045 \mathrm{~kg}$

\subsection{Variation of Efficiency with Time}

Figure 9 shows the comparison of the overall efficiency of the solar still of different models. The proposed model clearly has the lest efficiency, this is as expected due to low yield, occasioned by the influence of the cover angle and since other models are antecedents of the Dunkle's model with the negligence of evaporation in the analysis of free convection of air. The proposed model has a prac-

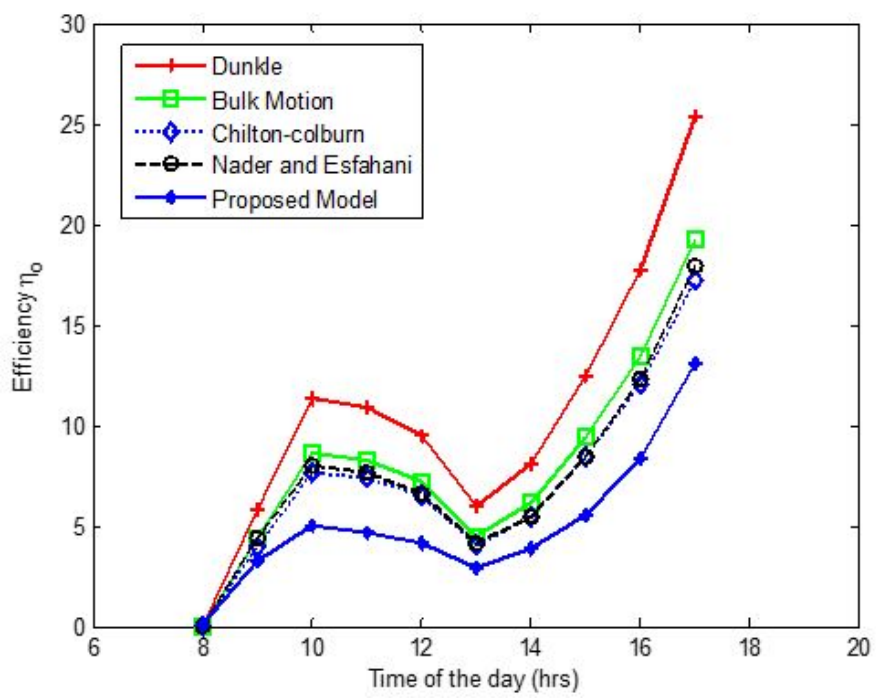

Figure 9: Comparison of Efficiency of the models with the experiment.

tical significance because it provides much information on the dependence of the heat transfer coefficient on the cover angle and is derived from first principle and is believed to be the best approach since it is without the over prediction in- 
herent in other models, all models however have the same profile.

\section{CONCLUSION}

Solar stills are technology for using solar irradiation to purify water. They provide clean water for domestic use in communities. Solar radiation focused on condensing cover heat up a mass of water till evaporation, separating the vapour from the impurities. On the basis of the results of investigating the solar still, a model was developed that captured the influence of the cover angle on still performance in terms of evaluating the heat transfer coefficient, yield and efficiency. The previous models of evaluating these matric has been shown to be unsatisfactory due to over prediction. The model was solved with MATLAB, and results show a well correlated trends with the established work of literature with the proposed model having the lest efficiency as the model is without the over prediction inherent in other models due to noninclusion of evaporation in the analysis of free convection of air. The proposed model has a practical significance because it provides much information on the dependence of the heat transfer coefficient on the cover angle and is derived from first principle. The peak yield of all the models occurs at about 11:00 AM, with the proposed model having a peak yield of about $0.045 \mathrm{~kg}$.

\section{References}

[1] M. Muthu, M. Kalidasa, and G. Esakkimuthu, "Different parameters affecting the rate of evaporation and condensation on passive solar still - A review," Renewable Sustainable Energy Review, vol. 38, pp. 309-322, 2014.

[2] A. El-Sebaii and E. El-Bialy, "Advanced designs of solar desalination systems: A review," Renewable Sustainable Energy Reviews, vol. 49, pp. 1198-1212, 2015.

[3] M. Chaibi, "An overview of solar desalination for domestic and agriculture water needs in remote arid areas," Desalination, vol. 127, no. 2, pp. 119-133, 2000.

[4] A. Kaushal, "Solar stills: A review," Renewable Sustainable Energy Review, vol. 14, pp. 446-453, 2010.

[5] P. Prakash and V. Velmurugan, "Parameters influencing the productivity of solar stills - A review," Renewable Sustainable Energy, vol. 49, pp. 585-609, 2015.

[6] R. Nader and J. Esfahani, "Productivity estimation of a single - slope solar still: Theoretical and numerical analysis," Energy, vol. 49, pp. 289-297, 2013.

[7] G. Lof, J. Eibling, and J. Bloemer, "Energy balances in solar distillers," American Institute of Chemical Engineers Journal, vol. 7, no. 4, pp. 641-649, 1961.

[8] B. Sharpley and L. Boelter, "Evaporation of water into quiet air from a one-foot diameter surface," Industrial \& Engineering Chemistry, vol. 30, no. 10, pp. 1125-1131, 1938.

[9] R. Dunkle, "Solar water distillation: the roof type still and a multiple effect diffusion still," in International Developments in Heat Transfer ASME, Proceedings of International Heat Transfer Part V, 1961, 895.

[10] V. Dwivedi and G. Tiwari, "Comparison of internal heat transfer coefficients in passive solar stills by different thermal models: An experimental validation," Desalination, vol. 246, no. 1, pp. 304-318, 2009.

[11] M. Corcione, "Effects of the thermal boundary conditions at the sidewalls upon natural convection in rectangular enclosures heated from below and cooled from above," International Journal of Thermal Sciences, vol. 42, pp. 199-208, 2003.

[12] T. Shawaqfeht, "New development in the theory of heat and mass transfer in solar stills," Solar Energy, vol. 55, no. 6 , pp. 527-535, 1995.
[13] P. Tsilingiris, "Modeling heat and mass transport phenomena at higher temperatures in solar distillation systems - The Chilton-Colburn analogy," Solar Energy, vol. 84 , no. 2 , pp. 308-317, 2010 .

[14] P. Dind and H. Schmid, "Application of solar evaporation to waste water treatment in galvanoplasty," Solar Energy, vol. 20, no. 4, pp. 205-211, 1977.

[15] P. Cooper, "Digital simulation of transient solar still processes," Solar Energy, vol. 12, pp. 313-331, 1969.

[16] M. Sodha, J. Nayak, U. Singh, G. Tiwari, and T. W, "Thermal performance of a solar still," Journal of Energy, vol. 5, no. 6, pp. 331-336, 1981.

[17] W. Szulmayer, "Solar stills with low thermal inertia," Solar Energy, vol. 14, no. 4, pp. 415-421, 1973.

[18] D. Aderibigbe, "Heat and mass transfer processes and the performance evaluation in single - Slope solar stills," Journal of Solar Energy Engineering, vol. 141, pp. 1-7, 2019.

[19] V. Baum and R. Bairamov "Heat and mass transfer processes in solar stills of hotbox type," Solar Energy, vol. 8, no. 3 , pp. 78-82, 1964. 